\title{
SGLT1 Deficiency Turns Listeria Infection into a Lethal Disease in Mice
}

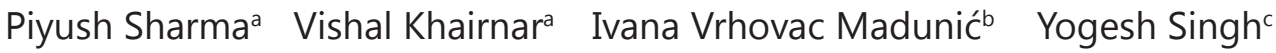 \\ Aleksandra Pandyra ${ }^{a}$ Madhuri S. Salker ${ }^{c}$ Hermann Koepsell ${ }^{d}$ Ivan Sabolić \\ Florian Lange Philipp A. Lang ${ }^{f}$ Karl S. Lang ${ }^{a}$
}

Institute of Immunology, University of Duisburg-Essen, Essen, Germany; ${ }^{b}$ Molecular Toxicology Unit, Institute for Medical Research and Occupational Health, Zagreb, Croatia; 'Department of Internal Medicine III, University of Tuebingen, Tuebingen Germany; 'Institute of Anatomy and Cell Biology,

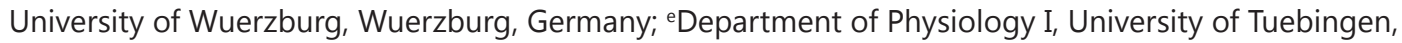

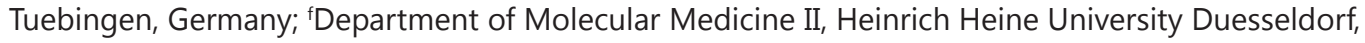
Duesseldorf, Germany

\section{Key Words}

Glucose uptake $\cdot \mathrm{Na}^{+}$-coupled glucose transport $•$ Listeria infection - TNF- $\alpha$ and IL-12a $\cdot$ Survival, -Liver • Spleen • Kidney • Lung • Bacterial clearance

\begin{abstract}
Background: Cellular glucose uptake may involve either non-concentrative glucose carriers of the GLUT family or $\mathrm{Na}^{+}$-coupled glucose-carrier SGLT1, which accumulates glucose against glucose gradients and may thus accomplish cellular glucose uptake even at dramatically decreased extracellular glucose concentrations. SGLT1 is not only expressed in epithelia but as well in tumour cells and immune cells. Immune cell functions strongly depend on their metabolism, therefore we hypothesized that deficiency of SGLT1 modulates the defence against bacterial infection. To test this hypothesis, we infected wild type mice and gene targeted mice lacking functional SGLT1 with Listeria monocytogenes. Methods: SGLT1 deficient mice and wild type littermates were infected with $1 \times 10^{4}$ CFU Listeria monocytogenes intravenously. Bacterial titers were determined by colony forming assay, SGLT1, TNF- $\alpha$, IL- 6 and IL-12a transcript levels were determined by qRTPCR, as well as SGLT1 protein abundance and localization by immunohistochemistry. Results: Genetic knockout of SGLT1 (Slc5a1-/ mice) significantly compromised bacterial clearance following Listeria monocytogenes infection with significantly enhanced bacterial load in liver, spleen, kidney and lung, and significantly augmented hepatic expression of TNF- $\alpha$ and IL-12a. While all wild type mice survived, all SGLT1 deficient mice died from the infection. Conclusions: SGLT1 is required for bacterial clearance and host survival following murine Listeria infection.
\end{abstract}

P. Sharma and V. Khairnar contributed equaly to this work.

Karl S. Lang

KARGER
Institute of Immunology, University of Duisburg-Essen, Essen, Germany

Hufelandstr. 55, 45147 Essen (Germany)

E-Mail KarlSebastian.Lang@uk-essen.de 


\section{Introduction}

Bacterial growth depends on availability of nutrients such as glucose and is augmented by hyperglycemia [1-8]. Extracellular glucose concentration could be lowered by cellular uptake and utilization of glucose. Glucose uptake could be accomplished by $\mathrm{Na}^{+}$-coupled glucose carriers SGLT1 and SGLT2 [9]. Unlike the facilitative glucose carriers of the GLUT family [10-12], the $\mathrm{Na}^{+}$-coupled glucose carriers can transport glucose against a chemical gradient and accomplish cellular glucose accumulation even at low extracellular glucose concentrations [9]. SGLT1 is expressed in intestinal epithelial cells and SGLT1 as well as SGLT2 in renal epithelial cells thus accomplishing the concentrative cellular uptake of glucose from the intestinal or renal tubular lumen across the apical cell membrane $[9,13]$. The low luminal glucose concentrations provide some protection against luminal bacterial growth and genetic or pharmacological inhibition of the carriers may favor the development of urinary tract infection $[14,15]$ and diarrhea $[16,17]$. SGLT1 expression is, however, not restricted to renal and intestinal epithelia [18], but has also been observed in heart [18, 19], lung [18], liver [18], tumor cells [20-27] and lymphocytes [28]. The expression of SGLT1 in lymphocytes prompted us to speculate that SGLT1 expression could modulate immune function during bacterial infection.

In the present study, we explored whether SGLT1 participates in the orchestration of anti-bacterial defense. To this end, SGLT1 deficient mice and their wild type littermates were intravenously infected with $1 \times 10^{4}$ CFU Listeria monocytogenes, and bacterial load, inflammatory cytokines, and survival determined.

\section{Materials and Methods}

\section{Mice}

The study was performed in age matched male SGLT1 deficient (Slc5a1-/-) and wild type $\left(\right.$ Slc5a1 $\left.1^{+/}\right)$ mice on C57BL/6J background. All animals were housed in single-ventilated cages in a controlled facility. Animal experiments were authorized by the Nordrhein Westfalen Landesamt für Natur, Umwelt und Verbraucherschutz (Recklinghausen, Germany), and in accordance with the German law for animal protection or according to institutional guidelines at the Ontario Cancer Institute of the University Health Network and at McGill University.

\section{Immunostaining and microscopy}

Immunohistochemistry in mouse tissue cryosections of spleen, small intestine and liver was performed using previously described protocols [16, 29, 30]. In short, tissue samples were fixed with 4\% $p$-formaldehyde, rinsed, and cut in $4 \mu \mathrm{m}$ thick cryosections which underwent antigen unmasking steps that included a microwave heating in $10 \mathrm{mM}$ citrate buffer $(\mathrm{pH} \mathrm{6.0)}$ ), followed by incubation with antibodies. The noncommercial rabbit-raised polyclonal mSglt1 antibody [16] was used diluted 1:50 at $4{ }^{\circ} \mathrm{C}$ overnight, followed by a commercial secondary antibody (Cy3-labeled goat anti-rabbit IgG, Jackson ImmunoResearch Laboratories, USA; dilution 1:800). The stained cryosections were covered with Vectashield (Vector Laboratories, USA), and inspected under the fluorescence microscope OPTON III RS (Opton Feintechnik, Germany). The images were taken with the attached SPOT RT digital camera and software (Diagnostic Instruments, USA), imported and processed in Adobe Photoshop. Additional immunofluorescent staining and histological analysis was performed on snap-frozen tissue as previously described [31]. In brief, sections were fixed with acetone for $10 \mathrm{~min}$, and non-specific antigens were blocked in phosphate-buffered saline (PBS) containing 2\% FCS for $10 \mathrm{~min}$, followed by various staining's for $45 \mathrm{~min}$. Images were acquired with a fluorescence microscope (KEYENCE BZ II analyzer).

\section{Isolation of total RNA, reverse transcription and qRT-PCR}

Total RNA from tissue samples was isolated by using TRIzol (Ambion, Thermo Fisher Scientific), reverse transcribed into cDNA using QuantiTect Reverse Transcription Kit (Qiagen). Quantitative real-time PCR was done by using SYBR green master mix (Applied Biosystems, Darmstadt, Germany) and analyzed by Roche light-cycler 480. For expression analysis of target genes, expression levels were normalized to GAPDH 
mRNA and calculated using the $\Delta$ Ct method. The following SYBR green primers were used purchased from Qiagen:

$\begin{array}{ll}\text { SGLT1: } & \text { QT00112679 } \\ \text { GAPDH: } & \text { QT01658692 } \\ \text { TNF } \alpha: & \text { QT00104006 } \\ \text { IL-6: } & \text { QT00098875 } \\ \text { IL-12a: } & \text { QT01048334 }\end{array}$

\section{Listeria infection}

SGLT1 deficient mice and littermate controls were infected intravenously by $1 \times 10^{4}$ CFU listeria monocytogenes and followed during the course of infection. Mice were sacrificed 48 hours later and organs were frozen in tissue-tek for immunohistological analysis. Liver sections were cut at $8 \mu$ in cryotome and stained using anti-listeria (clone LZA2, Santa Cruz) followed by secondary anti-mouse FITC-labeled IgG (Jackson ImmunoRes.) and Ly-6G and F480 for granulocytes and macrophages, respectively. Images were taken at fluorescent digital microscope (Keyence BZ 9000).

For detection of bacterial load, colony forming assay was done in 24-well plates on brain-heart infusion agar. Organs were harvested 4 days post-infection, homogenized, diluted and plated on the agar plates. The plates were inoculated at $37^{\circ} \mathrm{C}$ for bacterial plaques, which were counted manually.

\section{Statistical analysis}

Data are provided as means $\pm \mathrm{SD}, \mathrm{n}$ represents the number of mice investigated. All experiments were done with at least 3 mice per group. Data were tested for significance using parametric unpaired Student t-test unless specified. Results with $\mathrm{p}<0.05$ were considered statistically significant.

\section{Results}

\section{SGLT1 expression in liver, spleen and intestine}

Quantitative RT-PCR was employed in order to define SGLT1 transcript levels in murine liver, spleen and small intestine (jejunum). In naïve mice, the SGLT1 transcript levels were in liver and spleen orders of magnitude smaller than those in intestine (Fig. 1A). Expression of SGLT1 was confirmed by immunohistochemistry (Fig. 1B). As expected, no appreciable staining was observed in tissues from SGLT1 deficient mice.

\section{SGLT1 sensitive bacterial clearance following Listeria monocytogenes infection}

As illustrated in Fig. 2A-D, the bacterial titers in liver, spleen, kidney and lung were

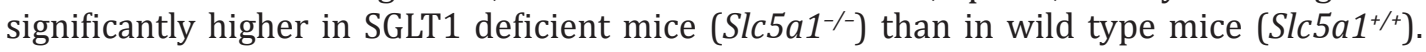
The observations were again confirmed by immunohistochemistry illustrating an enhanced

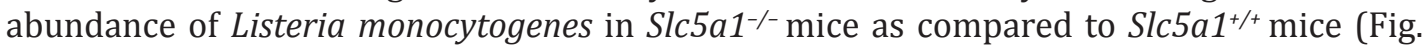
$2 \mathrm{E})$. While foci of replicating Listeria where highly infiltrated by granulocytes in Slc5a $1^{+/+}$

Fig. 1. SGLT1 expression in liver, spleen and small intestine. A: Arithmetic means \pm SD (n $=3$ /group) of SGLT1 transcript levels in naive mice showing its maximum expression in small intestine (SI) as compared to spleen and liver. B: Immunohistochemistry ( $n=3$ /group) of SGLT1 protein in spleen, jejunum (Small intestine) and liver of wild type (WT) and SGLT1 deficient (SGLT1 $\%$ ) mice, 48 hrs post-infection with $1 \times 10^{4}$ CFU Listeria monocytogenes intravenously. In WT mice, the protein was im-
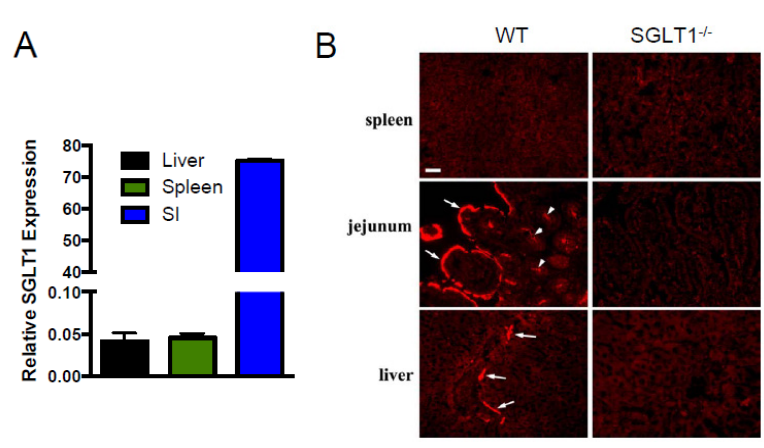
mune-localized to the brush-border membrane of jejunal enterocytes and luminal membrane of bile ducts, but not in spleen. The staining was absent in SGLT1 ${ }^{-/}$mice. Bar, $20 \mu \mathrm{m}$ (for all images). 
Fig. 2. Impairment of bacterial clearance in SGLT1 deficient mice. A-D: Bacterial titers in (A) liver, (B) spleen, (C) kidney and (D) lung of wild type mice (closed boxes) $(n=4)$ and SGLT1 deficient mice (open boxes) $(n=5)$, as measured by colony forming assay, $96 \mathrm{hrs}$ after $1 \times 10^{4}$ CFU Listeria monocytogenes infection. E: Immunohistochemical staining of monocytes forming granulomas in liver sections of control and SGLT1 deficient mice, $48 \mathrm{hrs}$ (n=3/group) and $96 \mathrm{hrs}$ (control $\mathrm{n}=$ 4, SGLT1 deficient $n=6$ ) post-infection with Listeria monocytogenes representing less granulomas and thus bacterial clearance in control mice. F: Arithmetic means \pm SD ( $n=$ 3 /group) of granulomas quantified by Image J analysis 48 hrs post-infection with Listeria monocytogenes in WT and SGLT1 deficient mice (F480 = F480 positive macrophages, Ly$6 \mathrm{G}=$ Ly-6G positive granulocytes $).{ }^{*}(\mathrm{p}<0.01)$, $* *(p<0.001), * * *(p<0.0001)$ indicate significant difference between SGLT1 deficient mice and wild type mice.
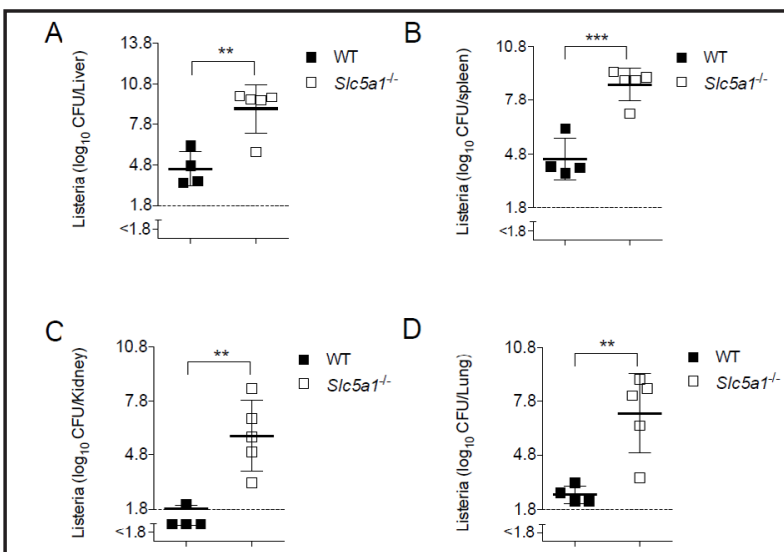

E

F
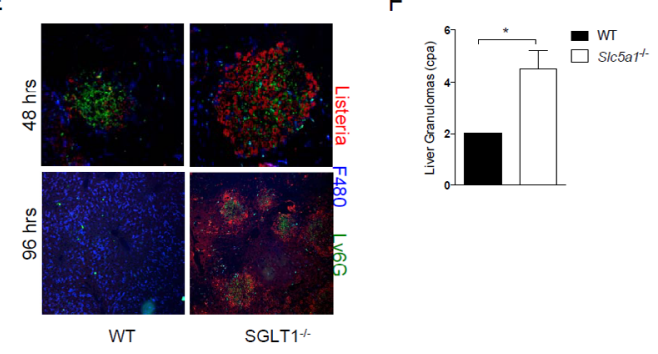

mice, Slc5a1-/- mice showed only limited granulocyte infiltration in relation to Listeria growth (Fig. 2E). Therefore Slc5a1-/- mice showed enhanced numbers of granuloma, which contain massive Listeria but little granulocytes (Fig. 2F).

\section{Anti-bacterial response in wild type and} SGLT1 deficient mice

Following infection with Listeria monocytogenes the hepatic TNF- $\alpha$ and IL-12a transcript levels increased to significantly higher values in Slc5a1/- mice than in Slc5 $a 1^{+/+}$mice. The transcript levels of IL-6 similarly tended to increase to higher values

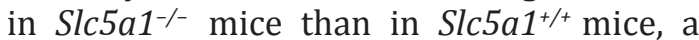
difference, however, not reaching statistical significance. In the spleen, TNF- $\alpha$ transcript levels increased again to significantly higher

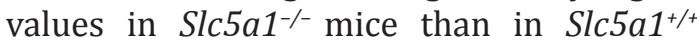
mice, whereas the splenic IL-6 and IL-12a transcript levels were similar in Slc5a1-/ mice and in Slc5a1 ${ }^{+/+}$mice (Fig. 3).

Survival of wild type and SGLT1 deficient mice following a Listeria monocytogenes infection

As illustrated in Fig. 4A, all Slc5a1+/+ mice survived the Listeria monocytogenes

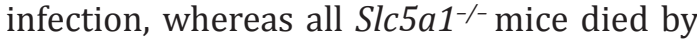

A

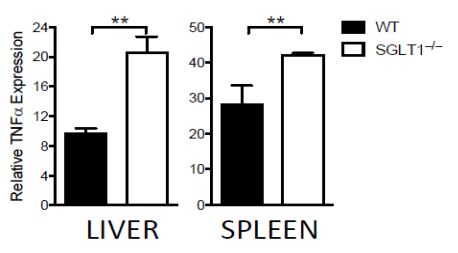

B

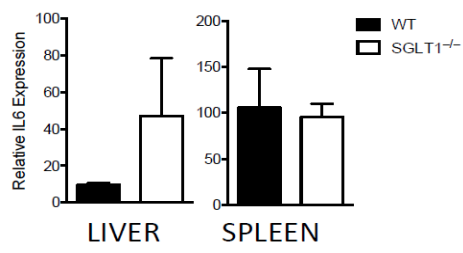

C

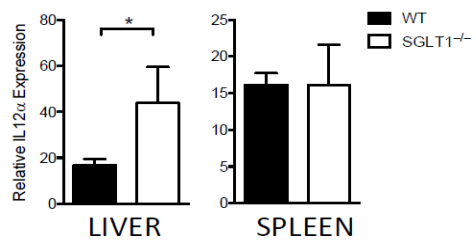

Fig 3. Anti-bacterial response in wild type and SGLT1 deficient mice. A-C: Arithmetic means \pm SD of transcript levels of (A) TNF $\alpha$, (B) IL-6, and (C) IL-12a in liver (left panel) and spleen (right panel) in WT (black bars) and SGLT1 deficient mice (white bars), 48 hrs post-infection with $1 \times 10^{4} \mathrm{CFU}$ listeria monocytogenes intravenously ( $\mathrm{n}=3$ /group). ${ }^{*}(\mathrm{p}<0.01)$, $* *(p<0.001)$ indicate significant difference between SGLT1 deficient mice and wild type mice. 
Fig. 4. Lethal course of listeria monocytogenes infection in SGLT1 deficient mice. A: Survival analysis of wild type mice and SGLT1 deficient mice after intravenous infection with $1 \times 10^{4} \mathrm{CFU}$ Listeria monocytogenes. While $100 \%$ of SGLT1 deficient mice died from the infection, all wild type mice survived (n = 7/group). B: Survival analysis of WT

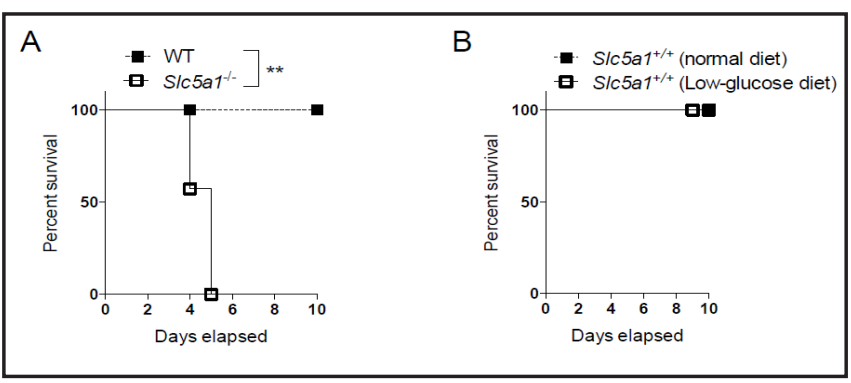
$\left(\right.$ Slc5 $\left.\mathrm{a1}^{+/+}\right)$mice maintained on normal or low-glucose diet after $1 \times 10^{4} \mathrm{CFU}$ listeria monocytogenes intravenous infection ( $\mathrm{n}=4$ /group). ${ }^{* *}(\mathrm{p}<0.001)$ indicate significant difference between SGLT1 deficient mice and wild type mice (Mantel-cox test).

day five from the infection. As Slc5a1-/-mice lack SGLT1, they were maintained on low-glucose diet. To test whether the diet has any effect on outcome of listeria infection, we maintained Slc5a1 $1^{+/+}$mice on either control diet or low-glucose diet for 3 weeks and then subjected the animals to $1 \times 10^{4} \mathrm{CFU}$ Listeria monocytogenes infection. As a result, the infection outcome

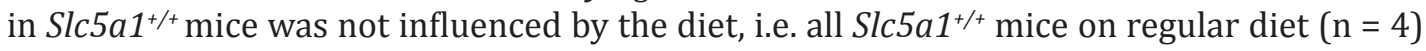
and low-glucose diet $(n=4)$ survived the infection (Fig. 4B). Thus, the different diets did not account for the impaired anti-bacterial response following Listeria infection in Slc5a1-/mice.

\section{Discussion}

The present study demonstrates for the first time that the high affinity $\mathrm{Na}^{+}$coupled glucose transporter SGLT1 participates in the orchestration of the host defense against a Listeria monocytogenes infection. Following systemic infection with Listeria monocytogenes the pathogen enters the liver, the main target organ of Listeria [32]. The pathogen is similarly found in the spleen and, to a lesser extent, in kidney and lung. More importantly, lack of SGLT1 leads to excessive bacterial growth, and enhanced formation of granulomas. SGLT1 deficiency thus has a striking influence on animal survival following Listeria monocytogenes infection. While all wild type mice survived, all SGLT1 deficient mice died from the infection.

The present observations raise the question, how the host cell SGLT1 expression and function is critically important for the limitation of bacterial load. SGLT1 may be critically important for the function and survival of the major anti-bacterial innate immune cells, granulocytes and macrophages. Obviously, these innate immune cells require glucose degradation by glycolysis for ATP generation [33,34]. ATP is mainly generated from glycolysis under aerobic and anaerobic conditions $[35,36]$. Lack of SGLT1 may thus compromise glucose uptake, function and survival of granulocytes entering infected tissue with low extracellular glucose concentration. In addition, metabolism can regulate immune functions $[37,38]$. Therefore lack of SGLT1 might induce an oxidative metabolism in granulocytes which could limit their function and survival [39]. At least in theory, SGLT1 expression in host cells may further influence the growth of bacteria by lowering the extracellular glucose concentration in areas of bacterial growth. SGLT1 accomplishes uphill transport of glucose, driven by the steep electrochemical gradient of $\mathrm{Na}^{+}$across the cell membrane [9]. Low extracellular glucose concentrations were expected to compromise bacterial growth and survival. Thus, the present observations could reflect SGLT1-dependent clearance of glucose from extracellular fluid curtailing nutrient supply of the pathogen. Further possibilities cannot be ruled out. In any case, the present observations reveal that SGLT1 is critically important for the host defense against Listeria monocytogenes.

Cellular glucose uptake by $\mathrm{Na}^{+}$-coupled requires subsequent ATP-consuming extrusion of the co-transported $\mathrm{Na}^{+}$by the $\mathrm{Na}^{+} / \mathrm{K}^{+}$ATPase. Energy depletion impairs extrusion of the co- 
transported $\mathrm{Na}^{+}$leading to cellular $\mathrm{K}^{+}$loss, depolarization, $\mathrm{Cl}^{-}$entry, cellular accumulation of $\mathrm{NaCl}$ with osmotically obliged water and thus cell swelling [40]. As $\mathrm{Na}^{+} / \mathrm{K}^{+}$ATPase extrudes $3 \mathrm{Na}^{+}$ions for one ATP, the energy required for extrusion of co-transported $\mathrm{Na}^{+}$is, however, only a fraction of the energy gained by glucose degradation, even if glucose is utilized for ATP generation by glycolysis without oxidative metabolism.

The present observations raise a potential caveat in the use of SGLT1 inhibitors for the treatment of diabetes and cancer $[17,41]$. The inhibitors may, similar to genetic knockout of SGLT1, compromise the host defense against bacteria and thus lead to lethal infections. Whether humans are similarly sensitive to lack of SGLT1 as mice, however, remains to be shown.

In conclusion, during Listeria monocytogenes infection SGLT1 apparently plays a decisive role in the host defense against this pathogen. Accordingly, SGLT1 deficiency leads to excessive bacterial load in several organs and turns Listeria monocytogenes infection into a lethal disease.

\section{Acknowledgements}

The authors acknowledge the meticulous preparation of the manuscript by Lejla Subasic. This study was supported by the Deutsche Forschungsgemeinschaft, GRK 1302, GRK1949, TRR60, SFB 773 B4/A1, La 315/15-5.

\section{Disclosure Statement}

None.

\section{References}

1 Baker EH, Clark N, Brennan AL, Fisher DA, Gyi KM, Hodson ME, Philips BJ, Baines DL, Wood DM: Hyperglycemia and cystic fibrosis alter respiratory fluid glucose concentrations estimated by breath condensate analysis. J Appl Physiol (1985) 2007;102:1969-1975.

-2 Baker EH, Wood DM, Brennan AL, Clark N, Baines DL, Philips BJ: Hyperglycaemia and pulmonary infection. Proc Nutr Soc 2006;65:227-235.

-3 Philips BJ, Redman J, Brennan A, Wood D, Holliman R, Baines D, Baker EH: Glucose in bronchial aspirates increases the risk of respiratory MRSA in intubated patients. Thorax 2005;60:761-764.

4 Rueda AM, Ormond M, Gore M, Matloobi M, Giordano TP, Musher DM: Hyperglycemia in diabetics and nondiabetics: effect on the risk for and severity of pneumococcal pneumonia. J Infect 2010;60:99-105.

-5 Gill SK, Hui K, Farne H, Garnett JP, Baines DL, Moore LS, Holmes AH, Filloux A, Tregoning JS: Increased airway glucose increases airway bacterial load in hyperglycaemia. Sci Rep 2016;6:27636.

6 Mauriello CT, Hair PS, Rohn RD, Rister NS, Krishna NK, Cunnion KM: Hyperglycemia inhibits complement-mediated immunological control of S. aureus in a rat model of peritonitis. J Diabetes Res 2014;2014:762051.

7 Vallon V: Do tubular changes in the diabetic kidney affect the susceptibility to acute kidney injury? Nephron Clin Pract 2014;127:133-138.

$>8$ Sheu SM, Cheng H, Kao CY, Yang YJ, Wu JJ, Sheu BS: Higher glucose level can enhance the H. pylori adhesion and virulence related with type IV secretion system in AGS cells. J Biomed Sci 2014;21:96.

9 Wright EM, Turk E: The sodium/glucose cotransport family SLC5. Pflugers Arch 2004;447:510-518.

10 Mendez LE, Manci N, Cantuaria G, Gomez-Marin O, Penalver M, Braunschweiger P, Nadji M: Expression of glucose transporter-1 in cervical cancer and its precursors. Gynecol Oncol 2002;86:138-143.

11 Rudlowski C, Becker AJ, Schroder W, Rath W, Buttner R, Moser M: GLUT1 messenger RNA and protein induction relates to the malignant transformation of cervical cancer. Am J Clin Pathol 2003;120:691-698. 


\section{Cellular Physiology Cell Physiol Biochem 2017;42:1358-1365

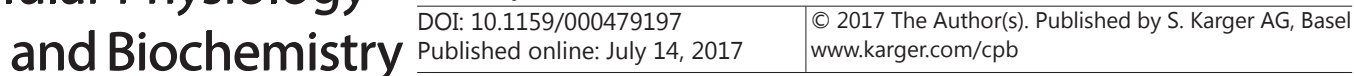

Sharma et al.: SGLT1 in Listeria Infection

12 Mueckler M, Thorens B: The SLC2 (GLUT) family of membrane transporters. Mol Aspects Med 2013;34:121-138.

13 Palazzo M, Gariboldi S, Zanobbio L, Selleri S, Dusio GF, Mauro V, Rossini A, Balsari A, Rumio C: Sodiumdependent glucose transporter-1 as a novel immunological player in the intestinal mucosa. J Immunol 2008;181:3126-3136.

14 Arakaki RF: Sodium-glucose cotransporter-2 inhibitors and genital and urinary tract infections in type 2 diabetes. Postgrad Med 2016;128:409-417.

15 Lang F: Risks and benefits of Sweet Pee. J Am Soc Nephrol 2011;22:2-5.

-16 Gorboulev V, Schurmann A, Vallon V, Kipp H, Jaschke A, Klessen D, Friedrich A, Scherneck S, Rieg T, Cunard R, Veyhl-Wichmann M, Srinivasan A, Balen D, Breljak D, Rexhepaj R, Parker HE, Gribble FM, Reimann F, Lang F, Wiese S, Sabolic I, Sendtner M, Koepsell H: Na(+)-D-glucose cotransporter SGLT1 is pivotal for intestinal glucose absorption and glucose-dependent incretin secretion. Diabetes 2012;61:187-196.

17 Tahrani AA, Barnett AH, Bailey CJ: SGLT inhibitors in management of diabetes. Lancet Diabetes Endocrinol 2013;1:140-151.

18 Vrhovac I, Balen Eror D, Klessen D, Burger C, Breljak D, Kraus O, Radovic N, Jadrijevic S, Aleksic I, Walles T, Sauvant C, Sabolic I, Koepsell H: Localizations of Na(+)-D-glucose cotransporters SGLT1 and SGLT2 in human kidney and of SGLT1 in human small intestine, liver, lung, and heart. Pflugers Arch 2015;467:18811898.

19 Szablewski L: Glucose transporters in healthy heart and in cardiac disease. Int J Cardiol 2017;230:70-75.

20 Casneuf VF, Fonteyne P, Van Damme N, Demetter P, Pauwels P, de Hemptinne B, De Vos M, Van de Wiele C, Peeters M: Expression of SGLT1, Bcl-2 and p53 in primary pancreatic cancer related to survival. Cancer Invest 2008;26:852-859.

21 Engelman JA, Cantley LC: A sweet new role for EGFR in cancer. Cancer Cell 2008;13:375-376.

-22 Ganapathy V, Thangaraju M, Prasad PD: Nutrient transporters in cancer: relevance to Warburg hypothesis and beyond. Pharmacol Ther 2009;121:29-40.

23 Ishikawa N, Oguri T, Isobe T, Fujitaka K, Kohno N: SGLT gene expression in primary lung cancers and their metastatic lesions. Jpn J Cancer Res 2001;92:874-879.

24 Kidd M, Modlin IM, Gustafsson BI, Drozdov I, Hauso O, Pfragner R: Luminal regulation of normal and neoplastic human EC cell serotonin release is mediated by bile salts, amines, tastants, and olfactants. Am J Physiol Gastrointest Liver Physiol 2008;295:G260-272.

25 Macheda ML, Rogers S, Best JD: Molecular and cellular regulation of glucose transporter (GLUT) proteins in cancer. J Cell Physiol 2005;202:654-662.

26 Matosin-Matekalo M, Mesonero JE, Delezay O, Poiree JC, Ilundain AA, Brot-Laroche E: Thyroid hormone regulation of the Na+/glucose cotransporter SGLT1 in Caco-2 cells. Biochem J 1998;334 ( Pt 3):633-640.

27 Weihua Z, Tsan R, Huang WC, Wu Q Chiu CH, Fidler IJ, Hung MC: Survival of cancer cells is maintained by EGFR independent of its kinase activity. Cancer Cell 2008;13:385-393.

28 Bhavsar SK, Singh Y, Sharma P, Khairnar V, Hosseinzadeh Z, Zhang S, Palmada M, Sabolic I, Koepsell H, Lang KS, Lang PA, Lang F: Expression of JAK3 Sensitive Na+ Coupled Glucose Carrier SGLT1 in Activated Cytotoxic T Lymphocytes. Cell Physiol Biochem 2016;39:1209-1228.

-29 Balen D, Ljubojevic M, Breljak D, Brzica H, Zlender V, Koepsell H, Sabolic I: Revised immunolocalization of the Na+-D-glucose cotransporter SGLT1 in rat organs with an improved antibody. Am J Physiol Cell Physiol 2008;295:C475-489.

-30 Sabolic I, Vrhovac I, Eror DB, Gerasimova M, Rose M, Breljak D, Ljubojevic M, Brzica H, Sebastiani A, Thal SC, Sauvant C, Kipp H, Vallon V, Koepsell H: Expression of Na+-D-glucose cotransporter SGLT2 in rodents is kidney-specific and exhibits sex and species differences. Am J Physiol Cell Physiol 2012;302:C1174-1188.

31 Recher M, Lang KS: Innate (over)immunity and adaptive autoimmune disease. Curr Top Microbiol Immunol 2006;305:89-104.

32 Mackaness GB: Pillars article: cellular resistance to infection. J. Exp. Med. 1962. 116: 381-406. J Immunol 2014;193:3185-3221.

-33 Maciver NJ, Jacobs SR, Wieman HL, Wofford JA, Coloff JL, Rathmell JC: Glucose metabolism in lymphocytes is a regulated process with significant effects on immune cell function and survival. J Leukoc Biol 2008;84:949-957.

34 Meszaros K, Bojta J, Bautista AP, Lang CH, Spitzer JJ: Glucose utilization by Kupffer cells, endothelial cells, and granulocytes in endotoxemic rat liver. Am J Physiol 1991;260:G7-12. 


\section{Cellular Physiology Cell Physiol Biochem 2017;42:1358-1365 \begin{tabular}{l|l|l} 
DOI: 10.1159/000479197 & O 2017 The Author(s). Published by S. Karger AG, Basel \\
www.karger.com/cpb
\end{tabular}}

Sharma et al.: SGLT1 in Listeria Infection

-35 Borregaard N, Herlin T: Energy metabolism of human neutrophils during phagocytosis. J Clin Invest 1982;70:550-557.

-36 Sbarra AJ, Karnovsky ML: The biochemical basis of phagocytosis. I. Metabolic changes during the ingestion of particles by polymorphonuclear leukocytes. J Biol Chem 1959;234:1355-1362.

37 Balmer ML, Ma EH, Bantug GR, Grahlert J, Pfister S, Glatter T, Jauch A, Dimeloe S, Slack E, Dehio P, Krzyzaniak MA, King CG, Burgener AV, Fischer M, Develioglu L, Belle R, Recher M, Bonilla WV, Macpherson AJ, Hapfelmeier S, Jones RG, Hess C: Memory CD8(+) T Cells Require Increased Concentrations of Acetate Induced by Stress for Optimal Function. Immunity 2016;44:1312-1324.

-38 Gaitan S, Escribano S, Sancho P, Cuenllas E, Tejero C: Glucose metabolism in bone marrow cells and granulocytes of adult mice after X-ray (5 Gy) irradiation: relationship to cell functionality. Br J Haematol 1997;96:559-565.

39 Moussa K, Michie HJ, Cree IA, McCafferty AC, Winter JH, Dhillon DP, Stephens S, Brown RA: Phagocyte function and cytokine production in community acquired pneumonia. Thorax 1994;49:107-111.

40 Lang F, Busch GL, Ritter M, Volkl H, Waldegger S, Gulbins E, Haussinger D: Functional significance of cell volume regulatory mechanisms. Physiol Rev 1998;78:247-306.

41 Koepsell H: The Na+-D-glucose cotransporters SGLT1 and SGLT2 are targets for the treatment of diabetes and cancer. Pharmacol Ther 2016;10.1016/j.pharmthera.2016.10.017 